\title{
Direito Ambiental e Comércio InTERnacional: O PRINCÍPIO DA PRECAUÇÃO E SUA APLICAÇÃO NO ÂMBITO DA Organização Mundial de Comércio
}

\section{Raul Loureiro Queiroz ${ }^{1}$}

Introdução. I. O Direito Ambiental e sua relação com o comércio internacional; A) O comércio internacional e sua lógica de funcionamento; B) O livre comércio e as políticas de preservação do meio ambiente: uma convivência conflitante. II. O princípio da precaução e sua interpretação no âmbito da Organização Mundial de Comércio $(\mathrm{OMC})$; A) Os princípios norteadores do Direito Ambiental: o princípio da Precaução; B) O princípio da Precaução e sua aplicação na resolução de controvérsias na OMC; B.1) A OMC: histórico e forma de solução de controvérsias; B.2)A aplicação do princípio da precaução na OMC. Conclusão. Bibliografia.

\section{INTRODUÇÃO}

$\mathrm{O}$ atual desenvolvimento dos mecanismos do comércio global ultrapassa, em muito, a velocidade com que novos tratados são firmados sobre o tema, transformando o atual estágio do fenômeno da globalização em um processo cuja dinâmica não mais se mede em anos, mas, por vezes, até em instantes. Dentro desse prisma, o debate acerca do comércio internacional é de tal amplitude que envolve não só a ciência do Direito mas também a Economia e a Política entre outras. Na própria ciência do Direito, diversos ramos ocupam-se em estudar esta matéria e suas implicações, mesmo que ainda não diretamente, com o que podemos afirmar que há sem dúvida, que a estreita relação entre as Ciências do Direito e da Economia tende a um aprofundamento cada vez maior ${ }^{2}$. Esta amplitude, todavia, não

1 Mestrando em Direito Internacional na Universidade Federal do Rio Grande do Sul (UFRGS).

2 Nesse sentido as palavras de LOBO TORRES: "Intuitivo que assumindo a Economia a postura de ciência valorativa, teria que se abrir a pesquisa interdisciplinar e se relacionar mais estreitamente com o direito, até como conseqüência da superação da dicotomia antes existente no plano objetivo entre Direito e Economia ou da consideraçäo daquele como superestrutura desta. É assunto dos nossos dias o estudo da Teoria Econômica do Direito, que desborda o método e o objeto da Teoria Jurídica da Economia.". in TORRES, Ricardo Lobo. Curso de direito financeiro e tributário. 6. ed. Rio de Janeiro: Renovar, 1999. 
decorre única e exclusivamente do aspecto econômico, eis que isso implica, obviamente, em reflexos sobre a atividade privada entre particulares e também, em diversas ocasiões, em uma verdadeira questão de Estado, o que traduz sua utilização em verdadeira atividade multidisciplinar entre ciências ${ }^{3}$. Decorre, também, do fato de que o crescimento das atividades produtivas implica na utilização em escalas cada vez maiores de mão de obra (e, portanto, tendo implicação até na livre circulação de pessoas no globo) e também de recursos naturais, o que, em muitas vezes, ocorre sem maiores critérios ou preocupações com as conseqüências, surgindo, assim, a ingerência da atividade de comércio global em outro ramo do Direito que não o do Direito Internacional ou do Direito Econômico: o campo do Direito Ambiental.

O Direito Ambiental é, talvez, o campo de aplicação do Direito Internacional que de forma mais rápida tem se aperfeiçoado e experimentado mudanças. De maneira simultânea seu espaço no debate jurídico amplia-se com a mesma rapidez, especialmente no âmbito do Direito Internacional. Os instrumentos de soft law normalmente associados a este ramo da ciência do Direito não mais são vistos como mera peça de retórica, mas sim como ferramentas de reconhecida efetividade ${ }^{4}$.

O primeiro obstáculo para uma maior interação entre os temas do meio ambiente e do comércio global está na crescente primazia do ponto de vista econômico sobre a questão envolvendo o tema do comércio especificamente. A visão puramente econômica acerca do comércio internacional, restringe a preocupação com o meio ambiente a um segundo plano de tal forma que esse acaba por se constituir em um entrave, um obstáculo. A visão de sob a ótica dita 'de metcado' busca tão somente a maximização sem uma preocupação maior com as conseqüências advindas das atividades produtivas. A nós pode parecer óbvio que os recursos naturais de nosso planeta possuem limites e que estamos nos aproximando perigosamente de seu esgotamento. Todavia, para fazer justiça aos argurnentos econômicos, devemos também compreender que os interesses privados também possuem fundamentos sociais. Como justificar a uma colônia de pescadores que há séculos sobrevive da prática de pesca de atuns que eles terão de modificar sua atividade em razão de outras espécies afetadas? Sem ajuda governamental para que se busque uma atividade alternativa para essas pessoas, será que não os estaríamos condenando à fome e à miséria? E se houver essa opção de redirecionamento da atividade com interferência estatal haverá orçamento para tanto sem comprometer outras áreas sensíveis? Mais: estarão os próprios pescadores em condições de uma reeducação no curto espaço de tempo que talvez a medida exija? Essas questões não são de simples resolução, e respondê-las pode ser mais complexo do que se imagina.

3 "The goal of Law and Economics analysis is to identify the legal implications of this maximazing behavior, both in and out markets and other institutionas." In: DUNOFF, Jefrrey L. TRACHTMAN, Joel P. The Law and Economics of Humanitarian Law Violations and Internal Conflict.American Journal of International Law. Vol. 93. April 1999. Cambridge: Cambridge University Press. P. 395.

4 "Environmental law has been recognised as one of the most effective tools to translate key global environmental goals and principles into action." HANNAM, Ian e BOER, Ben. Land Degradation and International Environmetal Law. Anais do $4^{\circ}$ Congresso Internacional de Direito Ambiental. São Paulo: IMESP 2000. P. 39. 
Todavia, não dar resposta alguma não é a saída, significaria apenas postergar a análise de um problema que está diante de nossos olhos a todo momento. O Direito Ambiental não é um simples conjunto de princípios morais elaborados por uns poucos que, de repente, resolvem levantar uma bandeira em defesa do meio ambiente, mas sim um ramo do Direito, com objeto bem definido e a preocupação de, dentro do debate jurídico, garantir à humanidade as necessárias condições para um desenvolvimento e crescimento permanentes, respeitando a natureza e os princípios gerais do Direito. Daí porque a importância de que se busque a implementação de seus princípios internacionalmente reconhecidos junto à atividade comercial mundial, uma vez que é nesse contexto que tem surgido as maiores discussões sobre os limites do desenvolvimento e dos processos de integração e concorrência entre indivíduos, empresas e até Nações.

O objetivo desse estudo é examinar no âmbito da maior organização internacional com finalidade de regular o comércio internacional, a Organização Mundial de Comércio (OMC), a aplicação de um dos mais controvertidos princípios do Direito Ambiental Internacional: o princípio da precaução (precautionary principle) cujo alcance e conteúdo não são objeto de consenso tanto entre doutrinadores como nos principais organismos internacionais. A partir de um exame acerca dos fundamentos do comércio internacional e da $\mathrm{OMC}$, será feita a análise da definição do referido princípio e de sua interpretação corrente nas controvérsias de comércio internacional, para que se possa ao final refletir acerca das perspectivas de sua utilização como forma de racionalizar o comércio mundial e sua complexa relação com a defesa do meio ambiente.

\section{O DIREITO AMBIENTAL E SUA RELAÇÃO COM O COMÉRCIO INTERNACIONAL}

\section{A. O comércio internacional e sua lógica de funcionamento}

O comércio internacional, e aqui o assunto será tratado excetuando-se o comércio de serviços, envolve, principalmente, a atividade de compra e venda de mercadorias além das fronteiras nacionais. Nesse aspecto suprarıacional é que está a grande diferença da atividade comercial pura e simples: a existência de agentes econômicos em diferentes países. Quando se fala de comércio internacional, não é viável pensar na aplicação das teorias econômica e jurídica da mesma forma que é pensado no âmbito interno de um determinado país ${ }^{5}$. Os interesses e implicações são de tal forma distintos que o debate ocorre em ramos diversos do debate interno em todas as ciências envolvidas, mormente o Direito e a Economia.

\footnotetext{
5 "Regulating the econoy in the international arena obviously differs from regulating a domestic economy, and issues which may be relevant in the international context may not necessery apply at the domestic level“". KWAKWA, Edward. Regulating the International Economy. The role of law in international politics: essays in international relations and international law. Oxford: Oxford University Press. 2000. P. 245.
} 
Segundo WATHEN pode-se, para fins didáticos, proceder na análise do mesmo pode ser feita sob três diferentes enfoques: protecionismo, livre comércio e comércio regulado ${ }^{6}$.

O protecionismo corresponde à proteção das indústrias nacionais da competição estrangeira. Foi a prática usual das nações até a primeira parte do século XX. Entretanto, o colapso econômico de 1929 que foi um dos fatores que levou à humanidade à Segunda Guerra Mundial praticamente esgotou a pura e simples utilização dessa prática sem maiores consequiências ${ }^{7}$. A forma mais usual de protecionismo é a utilização de tarifas diferenciadas de importação visando dificultar o ingresso dos produtos concorrentes estrangeiros no mercado interno. Outra forma está em arbitrar cotas de importação de produtos, restringindo a quantidade de produtos estrangeiros que ingtessam no país. O problema da utilização dessa prática consiste na utilização de idênticas represálias pelas outras nações e o que gera alto custo interno na tentativa de um auto-abastecimento que, invariavelmente, eleva os custos dos produtos para os cidadãos ou mesmo os deixa sem suprimentos daquilo que o país não tem condições de produzir internamente.

O livre comércio internacional, por sua vez, traduz-se no intercâmbio entre compradores e vendedores de diferentes países com pouca ou nenhuma interferência de seus governos. O conceito nuclear sob o qual se desenvolve a teoria do livre comércio é a teoria das vantagens comparativas. Por essa teoria, uma nação exporta aquilo em que é mais competitiva e importa o que não consegue produzir com menor custo. Exemplo: o Brasil, pela extensão e características, possui grande atividade agropecuária. Já o Japão, não dispõe dessas mesmas condições. Em contrapartida, a nação japonesa possui um parque tecnológico altamente desenvolvido em relação ao nosso. Assim, nada mais natural que exportemos os produtos agrícolas que os japoneses precisam, em troca da importação de eletroeletrônicos a um custo mais baixo do que seria sua produção no Brasil, inclusive com possibilidade de utilização de melhor tecnologia. Sua aplicação sem critérios, todavia, pode conduzir a uma desigualdade comercial, seja pelo atraso do desenvolvimento de um parque tecnológico brasileiro, seja porque o produto japonês possui um alto valor agtegado em comparação ao brasileiro, portanto as importações japonesas resultariam em desequilíbrio da nossa balança comercial.

Por derradeito o comércio regulado corresponde a uma tentativa de equilibrio entre os dois conceitos anteriores, cujo objetivo está justamente em evitar o fechamento ao comércio externo que advém no caso do protecionismo, mas sem deixar a indústria do país vulnerável como ocorre na utilização total dos ditames do livre comércio.

O estágio atual da teoria econômica está em propagar o livre comércio como a melhor forma de integração econômica internacional e promoção do desenvolvimento das

6 WATHEN, Tom. Um guia para el comercio internacional y el medio ambiente. Comercio Internacional y Medio Ambiente: Derecho, Economia y Política. Buenos Aires: Espaço Editorial. 1995.

7 Segundo o historiador E. J. HOBSBAWN: "Em suma, o mundo da segunda metade do século XX é incompreensível se não entendermos o impacto do colapso econômico". In HOBSBAWN, Eric J. Era dos Extremos: o breve século XX: 1914/1991. São Paulo: Companhia das Letras. 1995. P. 91. 
nações. O problema decorre do ideal não atingido do crescimento global eqüitativo, pois continuam a existir nações muito mais desenvolvidas do que outras cujo processo de crescimento foi por vezes até prejudicado pela adoção indiscriminada da visão de liberalização total de seus mercados. Isso decorre não apenas da impossibilidade dos países em desenvolvimento de acompanhar o ritmo de crescimento das nações mais desenvolvidas, mas também de que estas nem sempre agem da forma que apregoam quando se trata da abertura de seu próprios mercados internos ${ }^{8}$.

Como se esse impasse no impasse no debate econômico não bastasse, surge aqui a complexa questão do crescimento sustentável, isso é, de forma a preservar os recursos naturais para sua posterior utilização e garantir a qualidade de vida para as futuras gerações. Não basta que apenas pensemos em promover o comércio com a utilização daquilo que os países tem de melhor, mas também na implicação do consumo de recursos naturais para atingir esse fim, sob pena de esgotar-se a prática comercial ou causar danos irreversíveis não só ao meio ambiente, mas à própria economia de uma Nação. É esse aspecto que conduz a pauta da complexa relação entre a proteção do meio ambiente e a utilização das teorias econômicas.

\section{B. O livre comércio e as políticas de preservação do meio ambiente: uma convivência conflitante}

Em suas declarações, os economistas exaltam os benefícios globais do livre comércio e do crescimento econômico. Entretanto os prejuízos ambientais que podem decorrer desse incremento econômico são relegados ao conceito de externalidades, isso é custos não internalizados na produção e comercialização mundial de bens. O problema não é só no fato de que essas ditas externalidades são inúmeras e podem ter graves conseqüências, mas também que elas não reconhecem fronteiras nacionais e os seus prejuízos podem atingir até aqueles que não participaram da relação comercial ${ }^{9}$. Choca ainda mais o fato de que, embora as nações declarem abertamente que a preservação ambiental é uma meta a ser alcançada, muitas deixam de adotar os mesmos parâmetros de proteção reconhecidos internacionalmente sempre que observam que a preservação pode acabar conduzindo a um

8 Acerca do assunto as palavras do prêmio Nobel de Economia do ano de 2001, J. STIGLITZ: "O fato de a liberalização do comércio, na maior parte das vezes, não corresponder às promessas feitas - ao contrário, simplesmente gerar desemprego - é o que suscita oposição tão intensa. Mas a hipocrisia daqueles que insistem em tal liberalizaçäo - e a maneira como têm feito isso - tem, sem dúvida nenhuma, intensificado as hostilidades em relação ao assunto. O Ocidente forçou a liberalização do comércio para os produtos que exportava mas, ao mesmo tempo, continuou a proteger aqueles setores nos quais a concorrência dos países em desenvolvimento poderia representar uma ameaça à sua economia." In SiTGLITZ, Joseph. A globalização e seus malefícios. São Paulo: Futura. 2002. P. 93.

9 BACUS, Max. La política ambiental y los acuerdos sobre comércio: el nuevo nexo. Comercio Internacional y Medio Ambiente: Derecho, Economia y Política. Buenos Aires: Espaço Editorial. 1995. P. 327. 
reflexo negativo em sua balança comercial. Todos reconhecem a necessidade da proteção ambiental nos dias de hoje. Contudo, nem todos estão dispostos a impor barreiras ao comércio mundial em troca da preservação do meio ambiente, o que cria um potencial conflito que requet a imediata atuação do Direito Internacional como um todo. ${ }^{10}$

Bem evidenciando a ambigüidade de sentimentos que permeia o debate, JOHN H. JACCKSON salienta que duas correntes são observadas sobre o assunto ${ }^{11}$. A primeira reconhece a importância suprema da preservação do meio ambiente mesmo que a conseqüência seja a adoção de medidas restritivas ao comércio internacional. A segunda corrente afirma que a liberalização do comércio mundial é forma de promoção de bem-estar econômico e redução de desigualdades, portanto qualquer medida que se coloque contrária a isso estará sabotando o objetivo proposto. Evidencia-se que as duas propostas traduzem objetivos políticos bastante discrepantes, mas ambos de grande importância, colocando as autoridades em um dilema nem sempre de fácil resolução. O primeiro grande obstáculo está justamente nas duas correntes supramencionadas. Em geral os grupos que defendem uma ou outra proposta costumam ser hostis aos pontos de vista de seus oponentes. Os economistas e especialistas em política comercial não aceitam os argumentos dos ambientalistas, os quais acabam tendo a mesma postura. Em geral, são exatamente as diferentes visões econômicas e principalmente políticas sobre o tema que acabam conduzindo ao desacordo, quando a única forma de resolver o impasse está exatamente na cooperação e ajuda mútua entre os dois grupos antagônicos.

A busca da sintonia entre a política comercial e o meio ambiente é o desafio para o Direito Ambiental Internacional. Não basta mais somente que haja crescimento, mas, como referido anteriormente, que esse ocorra de forma sustentada. A análise das relações internacionais nos mostra que as Nações são cautelosas na adoção de medidas que possam ter impacto sobre a economia. Todavia, a chave para tesolver o impasse está justamente em pensar na questão de aceitar ou não um tratado sobre o assunto pensando a preservação do meio ambiente como parte de um processo estratégico de promoção da própria economia e dos interesses comerciais presentes e futuros ${ }^{12}$. O processo de globalização necessita de desenvolvimento conjunto, pois, do contrário, estará conduzindo a uma concorrência onde nações e indivíduos estarão indo na direção inversa de seus objetivos ${ }^{13}$.

${ }^{10}$ BACUS, Max. Ob. cit. p. 327.

11 JACKSON, John H. Las normas del comercio mundial y las políticas ambientales ¿congruencia o conflito? Comercio Internacional y Medio Ambiente: Derecho, Economia y Política. Buenos Aires: Espaço Editorial. 1995. P. 277.

12 HANNAM, Ian e BOER, Ben. Ob. cit. p. 39.

13 "La mundialización está causando estragos en muchas sociedades y contribuindo muy poco a la erradicación de la probreza." Organização Mundial para a Cooperação e Desenvolvimento Econômicos (OCDE). La mano visible: asumir la responsabilidad por el desarrollo social. Informe da OCDE para Genebra 2000. P. 2. 


\section{O PRINCÍPIO DA PRECAUÇÃO E SUA INTERPRETAÇÃO NO ÂMBITO DA ORGANIZAÇÃO MUNDIAL DE COMÉRCIO(OMC)}

\section{A. Os princípios norteadores do Direito Ambiental: o princípio da Precaução}

O Direito Ambiental é norteado por uma série de princípios cujos objetivos podem ser resumidos em dois conceitos básicos: preservação ambiental e busca do desenvolvimento sustentável ou sustentado ${ }^{14}$. A preocupação com o meio ambiente em âmbito global ganhou corpo a partir da década de 1970, quando o tema deixou as mesas dos pensadores ambientalistas e ganhou corpo nos debates diplomáticas, especialmente na Organização das Nações Unidas (ONU) através da Conferência realizada em 1972 em Estocolmo na Suécia. A Declaração de Estocolmo, resultado final mais marcante do evento, até hoje influencia os instrumentos de Direito Ambiental existentes, tendo em vista o compromisso assumido pelos representantes de 113 países de buscarem formas de trabalharem de maneira conjunta para a preservação e melhoria do ambiente em que vivemos.

Após Estocolmo, o segundo momento marcante da história recente do Direito Ambiental deu-se com a Conferência das Nações Unidas para o Meio-Ambiente e o Desenvolvimento (UNCED), também conhecida como RIO 92, uma vez que foi realizada no Brasil, na cidade do Rio de Janeiro. Nessa ocasião, não só foram reafirmados os propósitos da Conferência de Estocolmo, como estabelecidas as metas do compromisso de uma parceria global: a criação de novos níveis de coopetação envolvendo Nações soberanas e a sociedade ${ }^{15}$.

Atualmente, não há fonte de princípios norteadores do Direito Ambiental mais atualizada do que a Draft International Covenant on Environment and Development do International Union for Conservation of Nature and natural resources (IUCN), daqui para diante denominado Draft Covenant ou simplesmente Draft. Na Introdução à sua primeira edição o Draft afirma seus objetivos, explicitando, entre outras intenções, as de prover de suporte legal a integração dos conceitos de meio ambiente e desenvolvimento, desenvolver uma lista de princípios fundamentais objetivando um código de conduta e consolidar em único texto legal os muitos princípios de "soft law" sobre os temas de meio ambiente e desenvolvimento.

É interessante observar que, embora a denominação de princípios seja tão largamente utilizada de forma equivocada em nossa doutrina para definir aquilo que às vezes são regras de conduta (que não se confundem com princípios, como bem observa o Professor HUMBERTO AVILA, eis que estes últimos não determinam diretamente a conduta, mas

${ }^{14}$ Esses objetivos são bem evidenciados no art. $1^{\circ}$ do Draft International Covenant on Environment and Development do International Union for Conservation of Nature and natural resources (IUCN) que assim dispõe: "The objetive of this convenant is to achieve environmental conservationa as an indispensable component of sustainble development, through established rights and obligations"

${ }^{15}$ HANNAM, Ian e BOER, Ben. Ob. cit. p. 39. 
sim estabelecem fins relevantes $\left.{ }^{16}\right)$, os dez primeiros artigos são, efetivamente principiológicos, criando verdadeiras linhas mestras para a condução da atividade dos profissionais do campo do Direito Ambiental. Não há dúvidas sobre esse caráter uma vez que as premissas constantes nos primeiros artigos do Draft é de justamente enunciar os aspectos relevantes para a tomada de decisões no âmbito do Direito Ambiental ou para a formulação de tratados, não tendo a pretensão de esgotar o tema ou mesmo de terem aplicação imediata sem que possam ser por outros princípios de igual valor complementados para que justamente se alcance a finalidade almejiada ${ }^{17}$.

Dentre esses princípios, ao ser estabelecida uma relação entre diretrizes do Direito Ambiental e o Comércio Internacional, destaca-se por algumas características peculiares e pela amplitude de adoção de medidas que sua utilização enseja, aquele que está insculpido no art. $7^{\circ}$ do Draft: o princípio da precaução (precautionary principle). Segundo o texto do Draft, o princípio da precaução estabelece a necessidade de tomar as ações apropriadas para antecipar, prevenir e monitorar os riscos de potenciais danos sérios ou irreversíveis decorrentes de atividades diversas, mesmo que sem certeza científica ${ }^{18}$. A dimensão e o campo de aplicação já estão evidenciados na sua definição: derivado do princípio do artigo anterior (princípio da prevenção), ele pressupõe a necessidade de se agir quando houver evidências de atividades potencialmente nocivas, ainda que haja falta de certeza científica. O conceito prescinde da prova efetiva de que os danos ocorrerão, bastando a prova da potencialidade dos mesmos. Claro, o padrão desta prova deve ser criterioso, não se pode pura e simplesmente afirmar que há um perigo eminente ao meio ambiente, deve haver o que o Draft chama de "evidência convincente'. A premissa é atacar exatamente o risco potencial, antecipando danos sérios ou mesmo irremediáveis. A intensidade da ação depende da magnitude do risco, ainda assim, é indiscutivel o potencial de ação que dito princípio oferece, pois permite a adoção de medidas mesmo sem a absoluta certeza de que esse dano irá efetivamente acontecer.

O princípio da precaução aparece em diversos instrumentos de soft law da atualidade, assim como em tratados internacionais. Segundo CATHERINE TINKER o princípio pode tanto ser definido como uma variante do princípio legal de origem germânica de ação de precaução (Vorsorgeprinzip), como um conjunto de approaches regulatórios adotados pelos governos para a sua adoção ${ }^{19}$. A mesma opinião é compartilhada por outros doutrinadores, que vem sua origem como a reposta à necessidade de uma ação mais imediata, em determinadas condições, para que ocorresse uma efetiva proteção do meio ambiente ${ }^{20}$. A

16 AVILA, Humberto. Teoria dos Princípios. São Paulo: Malheiros. 2004. $4^{\text {a }}$ ed. Pp. 55.

17 AVILA, Humberto. Ob. cit. Pp. 68-69.

18 Draft International Covenant on Environment and Development, art. $7^{\circ}$ "Precaution requires taking appropriate action to antecipate, prevent and monitor the risks of potentialy serious or irreversible damage from human activities, even withiut scientific certainty."

19 TINKER, Catherine. State Responsability and the Precautionary Principle. The Precautionary Principle and International Law. Hague: Kluwer Law International. 1996. Pp. 55.

${ }^{20}$ KISS, Alexandre e SHELTON, Dinah. Manual of European Environmental Law. Cambridge: Grotuis Publications Limited. 1993. Pp. 37-38. 
primeira menção ao princípio de forma concreta, pode ser considerada a $1^{2}$ Conferência Internacional sobre a Proteção do Mar do Norte(1987) embora, além da definição constante no Draft, a outra referência mais importante acerca da sua utilização está presente na declaração resultante da RIO $92 .{ }^{21}$. O precautionary principle, portanto, baseia-se na idéia de salvaguarda, isso é, na noção de que, em caso de dúvida, há de prevalecer a preservação da saúde e do meio ambiente, ainda que inexista comprovação científica absoluta do dano potencial que se vislumbra, justificando sua potencialidade, por si só, a adoção de medidas com vistas a evitar sua ocorrência.

Embora haja uma evidente correlação com o princípio da prevenção, é preciso distingui-los. A opinião corrente na doutrina do Direito Ambiental é de que a prevenção implica uma avaliação de riscos para evitar danos e uma ação efetiva baseada no conhecimento existente, portanto, na presença de evidências científicas concretas ${ }^{22}$. Assim, podemos fazer a distinção entre os princípios da seguinte forma: em se havendo certeza sobre determinado fenômeno e das suas conseqüências, todavia não são desejadas ou não são convenientes suas conseqüências, isso é, seja por razão dos danos, seja por razões econômicas ou mesmo práticas, não é razoável aguardar o evento, estamos diante de uma situação de prevenção. A precaução, em contrapartida, advém da adoção de medidas mesmo quando o risco é ainda desconhecido no todo ou em grande parte, e sua mensurabilidade ou demonstração não é cientificamente comprovada de forma absoluta, ou seja falta a certez $a^{23}$. O reconhecimento internacional do princípio da precaução é de tal magnitude que o mesmo foi incluído no documento que consolidou a criação da União Européia, o Tratado de Maastrich de 1993, em seu art. 130. Com isso ele deixa de ser um simples instrumento de soft law, passando a ser considerado como verdadeira regra de Direito Costumeiro na Corte Européia de Justiçąa ${ }^{24}$. Isso não impede a mensuração necessária que sua utilização e interpretação requerem diante do caso concreto, mas traduz uma força normativa muito grande para sua aplicação.

\section{B. O princípio da Precaução e sua aplicação na resolução de controvérsias na OMC}

\section{B.1. A OMC: histórico e forma de solução de controvérsias}

A Organização Mundial de Comércio (OMC), organismo internacional por excelência imbuído de fiscalizar as relações comerciais internacionais, foi definida em texto de acordo

${ }^{21}$ Declaração RIO 92. Princípio 2 "Com a finalidade de proteger o meio ambiente, o princípio da precaução deverá ser aplicado pelos Estados de acordo com suas capacidades, Onde houver ameaças de riscos sérios ou irreversíveis, a falta de absoluta certeza científica não deve ser usada como razão para adiar medidas efetivas para prevenir a degradação ambiental".

${ }^{22}$ KISS, Alexandre e SHELTON, Dinah. Ob. cit. P. 37.

${ }^{23}$ CRETElla NETO, Jose. Direito Processual na Organização Mundial de Comércio - OMC. Rio de Janeiro: Editora Forense. 2003. Pp. 225-227.

${ }^{24}$ CRETELLA NETO, Jose. Ob. cit. P. 234. 
específico na Rodada Uruguai do GAT"T (General Agreement on Tariffs and Trade ou Acordo Geral de Tarifas e Comércio), amplo foro de negociações resultante das discussões ocorridas na Conferência de Bretton-Woods de 1944, cuja finalidade era a reconstrução da ordem financeira, econômica e política do mundo com o fim da $2^{2}$ Guerra Mundial. Em Bretton-Woods, o objetivo era a criação de três organizações intergovernamentais: o Fundo Monetário Internacional (FMI) o Banco Mundial (BIRD) e a Organização Internacional do Comércio (OIC). A ausência de consenso acerca desta última instituição, em particular a oposição do Congresso dos Estados Unidos da América do Norte à outorgar uma maior liberdade a um organismo internacional acerca de questōes que afetam a economia interna, acabaram por impedir a criação deste organismo. Com isso, foi possível apenas a celebração de um tratado em Genebra, em 1947, o qual correspondeu a criação do GATT.

O GATT materializou-se em encontros, denominados Rodadas de negociação ou simplesmente Rodadas, onde se discutiam alternativas e soluções visando a redução de barreiras tarifárias. A ausência de uma definição mais clara da abrangência do próprio GATT e de um acordo acerca da forma de solução de controvérsias, acabava por impor limites ao alcance das deliberações, afastando deste um aspecto mais jurídico das reivindicações, e relegando-o a um encontro diplomático negocial.

A mais ambiciosa de suas rodadas foi exatamente a última: a Rodada Utuguai, que, iniciada em 1986 e programada para durar não mais de três anos, acabou durando até 1994, tendo estabelecido, entre outros pontos, o estabelecimento do Acordo Geral sobre o Comércio de Serviços (GATS), a garantia da propriedade intelectual (tópico especialmente relevante para os países mais desenvolvidos) através do Acordo sobre Direitos de Propriedade Intelecutal Relacionados com o Comércio (TRIPs) e, em especial, a criação da Organização Mundial de Comércio (OMC), cujo funcionamento iniciou-se em 1\% $101 / 1995$.

Com a criação da OMC, a dinâmica do comércio internacional saía do protocolo de intenções diplomáticas, que por maiores que fossem os debates muitas vezes não geravam resultados concretos, e se ingressava em uma nova fase da liberação do comércio: a criação de um órgão dotado de poderes e a existência de um foro adequado para solução de controvérsias. A criação de um mecanismos para a resolução de controvérsias no comércio internacional (tema de extrema sensibilidade na agenda de todas as nações envolvidas no comércio mundial ante as múltiplas possibilidades de desequilíbrio interno das contas e crises sociais que podem ser causados por alterações na Balança de Pagamentos ou enxurrada de produtos estrangeiros), foi o grande resultado da chamada Rodada Uruguai ${ }^{25}$.

A criação da OMC incluiu também o estabelecimento do seu Órgão de Solução de Controvérsias (OSC), um sistema decisório de maior eficácia que o concebido no GATT, onde somente o consenso, inclusive do Estado que fosse vencido na demanda, permitia a

${ }^{25}$ HOWSE, Robert. The Legitimacy of the World Trade Organization. The legitimacy of international organizations. Tokyo: United Nations Unioversity Press. 2001. P. 358. 
implementação da decisão. Em primeiro lugar, o OSC é resultado de um tratado internacional que getou obrigação dos signatátios de tespeitar a decisão, exigindo-se a tegra do consenso (não só de um único Estado, mas de todos) somente para a rejeição de um relatório no Conselho da OMC. Em segundo lugar, foi estabelecido um Entendimento relativo às Normas e Procedimentos sobre Solução de Controvérsias, com artigos clatos sobte a condução e funcionamento dos trabalhos e o alcance das decisões e possibilidade de recurso.

A estrutura do OSC contempla a unificação de procedimentos para solução das controvérsias independente da matéria em debate, e a estipulação de prazos para a constituição e funcionamento dos painéis e para a apresentação de defesa formal por parte do Estado demandado, cabendo, inclusive, apelação. O Órgão de Apelação da OMC exerce verdadeiro controle jurídico sobre o processo dos painéis que ocorrem quando do funcionamento do Ótgão de Solução de Controvérsias ${ }^{26}$. A apelação tem, principalmente, o escopo de evitar a meta alegação de uma decisão "injusta" no caso em tela, seja por desconsiderar um argumento seja em decorrência de pretensa má interpretação. Todavia, importa salientar que o Órgão de Apelação deverá restringir sua apreciação às questões de direito ou interpretações judiciais.

A OMC possui, ainda, uma característica peculiar fundamental como Otganização Internacional, que é a possibilidade de impor sanção efetiva pelo descumprimento de suas normas (atípico no Direito Internacional eis que essa alternativa é normalmente rechaçada pelos Estados sob a alegação de ferit sua soberania). A sanção econômico-comercial da OMC implica em autorização de retaliações e de suspensão de benefícios assentidos previamente no ótgão entre seus membros. Isso tequer da $\mathrm{OMC}$ uma legitimidade de absoluta televância, pois há uma completa mudança acerca da percepção corrente da soberania das nações, permitindo-se não uma testrição a esta, mas sim uma efetividade de medidas pelas demais quando sentirem-se prejudicadas e assim foi reconhecido como resultado da disputa que tomar lugar no painel correspondente do Órgão de Solução de Controvérsias.

Essa característica é, sem dúvida, o motivo pelo qual a demanda pelo Organismo de Solução de Controvérsias seja muito maior que de qualquet outro tribunal ou foro permanente internacional, inclusive a Corte Internacional de Justiça (CIJ), que recebeu, em 30 anos de existência (desconsiderando-se o período anterior da Corte Internacional Permanente de Justiça) 93 casos até o ano 2000, enquanto a OMC, entre 1955 e 2000, teve submetidos 183 casos à sua apreciação ${ }^{27}$. Obviamente não é imperativo o ingresso da discussão no OSC. Importa lembrat, contudo, que As partes sempre poderão, mesmo estando a debater o caso no âmbito da OMC, recorrer aos meios diplomáticos tradicionais para a solução de controvérsias como os bons ofícios, a conciliação a mediação e a atbitragem. É essa maior efetividade da OMC para a resolução de conflitos que faz com que se procure a análise da possibilidade ou não de aplicação de urn princípio ambiental em seu âmbito.

\footnotetext{
${ }^{26}$ HOWSE, Robert. Ob. cit. P. 359.

${ }^{27}$ Dados disponíveis em http://www.un.org e http://www.wto.org acesso em 20 de abril de 2005.
} 


\section{B.2. A aplicação do princípio da precaução na OMC.}

O princípio da precaução não é universalmente aceito como regra do Direito Internacional, especialmente no âmbito da OMC. A possibilidade de divergência de interpretação do alcance do princípio advém diretamente da diferença entre princípios e regras aludida anteriormente. Os países da União Européia já de longa data o adotam como verdadeira norma de Direito Internacional, entendendo que se trata de regra costumeira diretamente aplicável, o que é feito com base na sua inclusão do Tratado constitutivo da União Européia ${ }^{28}$. Com outro ponto de vista sobre o assunto, os E.E.U.U. e o Canadá manifestam no âmbito da OMC que o referido princípio possui exatamente isso: caráter principiológico, portanto dotado de caráter indicativo, destinado a dar orientação para decisões, não sendo auto aplicável ${ }^{29}$.

$O$ artigo XX do GATT, antecessor da OMC, já oferecia a possibilidade de aplicação do princípio da precaução ao dispor em seu art. XX:

"... measures not applied in a member which would constitute a menas of arbitrary os injustifiable discrimination between countries where the same conditionas prevail, or a distinguished restiction on international trade, notbing in this Agreement shall be construed to prevent the adoption or enforcement by any contracting party of measures:... (b) necesseray to protect human, animal or plant life or health."

Perceba-se que, na aparência, o GATT possibilitava uma utilização abrangente do princípio da precaução. Na prática, todavia, as coisas se mostraram bastante diferentes. Ainda no âmbito do GATT, foi celebrado o Acordo sobre a Aplicação de Medidas Sanitárias e Fitossanitárias (SPS agreement). Este acordo visava, em tese, estabelecer regras para a adoção de medidas fitossanitárias ou sanitárias passíveis de utilização na autorizar restrição de comércio, sob a forma de proibição de venda de produtos ou retirada destes do mercado, quando na existência de avaliação prévia sob efeitos danosos à saúde. Entretanto, o SPS foi redigido de forma a permitir a circulação dessas mercadorias, exceto no caso de certeza científica, portanto colocando-se em oposição ao princípio da precaução, uma vez que esse possui como seu grande trunfo a possibilidade da incerteza, enquanto o SPS exige a certeza científica para que haja a possibilidade de utilização de barreiras ao comércio.

Ainda assim, um dos artigos do SPS agreement, o art. $5^{\circ}$, causou controvérsia entre os membros da OMC, que discutiam acerca da melhor forma de interpretação do mesmo. $\mathrm{O}$ referido artigo foi redigido com a intenção de fornecer as bases para a avaliação dos riscos potenciais que pudessem ser objeto de alguma imposição de medida sanitária ou

\footnotetext{
28 Tratado de Maastrich, art. 130.

29 CRETELLA NETO, Jose. Ob. cit.. Pp. 234.
} 
fitossanitária que impedisse o livre comércio sob a alegação de danos em potencial Estes riscos, segundo a redação do artigo devem levar em consideração a evidência científica disponível e os padrões estabelecidos pela comunidade científica internacional, os processos e métodos de testes e amostragens que levaram à conclusão e as condições ambientais e ecológicas dos envolvidos, entre outros fatores ${ }^{30}$.

Um caso bastante célebre e cuja decisão e fundamentos norteiam o debate sobre a possibilidade de aplicação do princípio da precaução na OMC até os dias de hoje foi o caso WT/DS26 EC - Measures Concerning Meat and Meat Products(Hormones) - Complaint by the United States, referido a partir de agora como simplesmente Hormones. Esse caso, basicamente, diz respeito ao seguinte: trata-se de Recurso cuja decisão final data de 1998, dirigido ao Órgão de apelação da OMC interposto pelos reclamantes (E.E.U.U. e Canadá) e também pela parte reclamada (a, então, Comunidade Européia), atacando decisão de controvérsia em que a interpretação dada a alguns artigos do SPS Agreement, não foi considerada adequada. Esta decisão era decorrente de Reclamações dos E.E.U.U. e do Canadá contra medidas restritivas de importação de carne por parte da Comunidade Européia sob a alegação de não aceitar carne em que os animais haviam sido submetidos a tratamento com hormônios, justamente em decorrência do princípio da Precaução, alegando, em síntese, a ausência de evidências científicas que comprovassem que aquela carne não traria prejuizos à saúde. Os painéis de ambas as disputas foram, em geral, desfavoráveis a Comunidade Européia, sob a alegação de que as medidas adotadas por esta última deveriam estar de acordo com as obrigações constantes do SPS agreement, devidamente acompanhadas de evidências científicas concretas, sem as quais haveria tão somente restrição ao comércio internacional, uma vez que não se dispunha de padrões (standards) teconhecidos por todos acerca da possibilidade ou não de utilização de hormônios nos animais. Todos recorreram com vistas a que fosse estabelecido, então, o padrão de interpretação das regras do SPS agreement, em especial do art. $5^{\circ}$, item 7 , não só para o caso concreto como para evitar discussões futuras ${ }^{31}$.

A decisão final do órgão de apelações da $\mathrm{OMC}$, nesse caso foi de que o princípio da precaução, por se tratar somente de um princípio, não poderia se sobrepor ao disposto no SPS agreement, uma vez que seria, no entendimento do Órgão de Apelação, ainda matéria de debate no próprio Direito Ambiental Internacional, afirmando que "The status of the precautionary principle in international law continues to be the subject of debate among academics, law practitioners, regulators and judges. The precautionary principle is regarded

30 SPS agreement, art. $5^{\circ}$

31 SPS agreement, art. 5.7. "In cases where relevant scientific evidence is insufficient, a Member may provisionally adopt sanitary or phytosanitary measures on the basis of available pertinent information, including that from the relevant international organizations as well as from sanitary or phytosanitary measures applied by other Members. In such circumstances, Members shall seek to obtain the additional information necessary for a more objective assessment of risk and review the sanitary or phytosanitary measure accordingly within a reasonable period of time" 
by some as having crystallized into a general principle of customary international environmental law. Whether it has been widely accepted by Members as a principle of general or customary international law appears less than clear ${ }^{\$ 32}$. Interessante observar, como alguns articulistas também já o fizeram, que em parte, foi deixada uma margem para aplicação do princípio da precaução, aceitando-se que exista alguma compatibilidade entre a avaliação de risco e as medidas regulatórias domésticas de competência de cada país em caso como o sob análise do Órgão de Apelação $0^{33}$.

A avaliação dos riscos foi considerada insuficiente, por não haver a chancela de algum organismo científico, na verdade um afastamento da verdadeira e precisa aplicação do princípio, pois é a incerteza que o diferencia dos demais ${ }^{34}$. Houve, é verdade, uma possibilidade de discussão do princípio da precaução para que fossem impostas barreiras ao

De qualquer maneira, houve admissão da pertinência da invocação do princípio da precaução, tendo sido feita ressalva, entretanto da ausência da certeza, $O$ que o tornou emblemático, pois, a partir de então, foi o único caso em que a argumentação do membro que pretendia com base no princípio da precaução foi aceita, uma vez que deixou claro que se houvesse uma prova científica mais contundente, ainda que não absoluta, poderia a Comunidade Européia ter obtido êxito em seu propósito. Contudo, uma vez em casos seguintes (v.g. WT/DS 76 Japan - Measures Affecting Agricultural Products), não houve sequer o acolhimento da argumentação japonesa que invocou o mesmo princípio, mostrando que o caso Hormones não se transformou em adoção de uma posição clata e bem definida da OMC acerca da aceitação do princípio da precaução, como justificativa para imposição de restrições ao comércio internacional (embora tanto no Direito Ambiental como no Direito do Consumidor haja larga utilização do mesmo). Para que tenhamos uma posição definitiva sobre o princípio no âmbito da OMC, será necessária uma controvérsia em que haja demonstração praticamente inequívoca dos riscos, o que, em verdade, nos remeteria ao outro princípio: o da prevenção. Estaríamos, na verdade, não incorporando o princípio da precaução, mas sim o adotando em conjunto com o outro supracitado princípio, o que fugiria do debate acerca da aceitação do princípio da precaução dentro da OMC ou não. Ainda assim somente o tempo poderá dizer a evolução sobre o assunto, uma vez que ainda não há marco regulatório que não o SPS, cuja aplicação conjunta com o princípio da precaução prescinde de uma aceitação de uma prevalência do interesse social sobre os interesses comerciais que não é a finalidade para a qual foi constituída a OMC.

32 Apelation WT/DS26/AB/R: EC Measures Concerning Meat and Meat Products (Hormones). Genebra: 1997. Disponível em <http//www.wto.com> acesso em 15.05.2005.

${ }^{33}$ HOWSE, Robert. Ob. cit. P. 393.

34 Apelation WT/DS26/AB/R: (Hormones). Ob. cit. p. 87. 


\section{CONCLUSÃO}

O Direito Ambiental está na sua fase de pleno amadurecimento, tendo reconhecimento como um dos mais importantes campos do Direito Internacional. O sucesso de iniciativas como a Conferência das Nações Unidas para o Meio-Ambiente e o Desenvolvimento (UNCED), a maior reunião de Chefes de Estado desde o fim da $2^{2}$ Guerra Mụndial, demonstra que a preocupação com o meio ambiente é global e não mais uma utopia de uns poucos. Todavia, entre o discurso e a prática há um distanciamento, demonstrado ao longo desse breve estudo que implica nas conseqüências da adoção de políticas ambientais em detrimento de outros setores sensíveis da sociedade. É nesse prisma que se insere a relação entre o comércio internacional e os princípios de Direito Ambiental. O princípio da precaução, que foi mais detalhadamente discorrido, implica, muitas vezes, na adoção de medidas que implicam restrições ao ideal econômico de livre comércio entre nações, com uma aplicação equilibrada da teoria das vantagens comparativas e uma promoção crescente de desenvolvimento em escala mundial. Dito princípio visa garantir a qualidade de vida da humanidade, mesmo que para isso precisemos tomar medidas que nem sempre são clara e precisamente justificáveis pela ciência, baseando-se em um certo empirismo. Para aqueles que se filiam à corrente que acreditam que o livre comércio é a melhor forma de se proporcionar desenvolvimento, com argumentos bastante sólidos, é difícil aceitar que um ideal de preservação possa impor obstáculos a esse pensamento de liberdade comercial.

Todavia, a existência de restrições ao livre comércio é justamente a ausência do correto funcionamento desse, e da impossibilidade de cumprimento das promessas que seus defensores manifestam, seja por falta de um verdadeiro ctescimento conjunto, seja pela ausência de equilíbrio na abertura dos mercados ${ }^{35}$. Aliado a isso, temos a velha questão que nos coloca diante do impasse dos escassos tecursos naturais e da forma predatória que são consumidos pela humanidade, tornando verdadeiros os temores de um futuro colapso de nosso ecossistema. Ora, se o quadro é tão decepcionante, o que se poderá fazer?

Na verdade, a resposta está na harmonização entre o livre comércio e a proteção do meio ambiente. É preciso parar de pensar nestes como campos estanques, mas sim compreendê-los como uma forma integrada de aplicação de regras e princípios de forma a realmente atingir todos os objetivos que ambos os lados da moeda explicitados por JOHN JACKSON pretendem alcançar ${ }^{36}$. A hostilidade é resultante da falta de interatividade, se ambos os grupos perceberem que a assistência e a cooperação mútuas poderão levar ao seus objetivos políticos, estaremos ingressando em uma nova fase desse debate ${ }^{37}$. Atingir uma harmonia e uma maior sintonia no que diz respeito ao Comércio Internacional não é tarefa

35 STIGLITZ, Joseph. Ob. cit. p. 94.

${ }^{36}$ JACKSON, John H. Ob. cit. P. 277.

${ }^{37}$ JACKSON, John H. Ob. cit. P. 278. 
tão simples assim. A própria palavra harmonização implicaria, inicialmente, na adoção de marcos regulatórios que obedeçam a um mesmo padrão, sob pena de inviabilizar que esses ideais saiam do campo das idéias e possam ser aplicados na prática ${ }^{38}$. Por óbvio, é sabido que a realidade não permite pensar em uma mudança tão drástica. Por isso mesmo, não á mudança política extrema que se deve buscar, mas sim, uma convergência de linhas políticas para que a aproximação resulte na adoção de uma linha que permita a promoção do comércio sem a degradação do meio ambiente.

É aqui que se abre, no prisma atual, o campo para a utilização dos princípios ambientais no âmbito da Organização Mundial de Comércio. Não é factível pensar que a preservação do meio ambiente irá se tornar o centro do debate em um organismo internacional que já possui desde sua criação uma preocupação primordial (promoção comercial) e está fundamentado em três pilares: livte comércio, livre concorrência e não discriminação, com o intuito de buscar a regulação e ampliação das trocas internacionais ${ }^{39}$. Entretanto, para chegarmos até a OMC foram necessários quase cinqüenta anos de existência de um acordo anterior (GATT), o que nos leva a pensar que talvez a questão ambiental não tenha esse tempo todo. Logo, é preciso buscar um local adequado para debater o assurito através dos mecanismos disponíveis. A conscientização da necessidade do livte comércio mundial - e não há dúvida de sua importância e relevância - não implica no abandono de outras preocupações: basta uma atuação conjunta de interesses. O papel do Direito nesse problema, está em coordenar a aplicação simultânea dos princípios e regras do Direito Internacional como forma de garantir que sejam respeitados os direitos de todas as partes envolvidas. A aplicação de um princípio não exclui o outro: a fixação de standards é que conduzirá a formação de precedentes que estabeleçam a necessária segurança jurídica que todos esperam, inclusive aqueles que possuem uma natural tendência para um ou outro lado, eis que a insegurança seguramente não é objetivo das partes, mas sim a aplicação do Direito como regulador de relações e conflitos.

${ }^{38}$ CHARNOWITZ, Steve. Armonización ambiental y política comercial. Comercio Internacional y Medio Ambiente: Derecho, Economia y Política. Buenos Aires: Espaço Editorial. 1995. P. 339.

${ }^{39}$ CRETELLA NETO, Jose. Ob. cit.. Pp. 1. 


\section{BIBLIOGRAFIA}

AVILA, Humberto. Teoria dos Princípios. São Paulo: Malheitos. 2004. $4^{2}$ ed.

BACUS, Max. La política ambiental y los acuerdos sobre cométcio: el nuevo nexo. Comercio Internacional y Medio Ambiente: Derecho, Economia y Política. Buenos Aires: Espaço Editorial. 1995.

CHARNOWITZ, Steve. Armonización ambiental y política comercial. Comercio Internacional y Medio Ambiente: Derecho, Economia y Política. Buenos Aires: Espaço Editorial. 1995.

CRETELLA NETO, Jose. Direito Processual na Organização Mundial de Comércio - OMC. Rio de Janeiro: Editora Forense. 2003.

DUNOFF, Jefrtey L. TRACHTMAN, Joel P. The Law and Economics of Humanitarian Law Violations and Internal Conflict. American Journal of International Law. Vol. 93. April 1999. Cambridge: Cambridge University Press.

HANNAM, Ian. BOER, Ben. Land Degradation and International Environmetal Law. Anais do $4^{\circ}$ Congresso Internacional de Direito Ambiental. São Paulo: IMESP 2000 .

HOBSBAWN, Eric J. Era dos Extremos: o breve século XX: 1914/1991. São Paulo: Companhia das Letras. 1995.

HOWSE, Robert. The Legitimacy of the World Trade Organization. The legitimacy of international organizations. Tokyo: United Nations Unioversity Press. 2001.

INTERNATIONAL UNION FOR CONSERVATION OF NATURE AND NATURAL RESOURCES (IUCN). Draft International Covenant on Environment and Development. Cambridge: Third edition. 2004.

JACKSON, John H. Las normas de comercio munidal y las políticas ambientales ¿congruencia o conflicto? Comercio Internacional y Medio Ambiente: Derecho, Economia y Política. Buenos Aires: Espaço Editorial. 1995.

KISS, Alexandre. The rights and Interests os Future Generations and the Precautionary Principle. The Precautionary Principle and International Law. Haia: Kluwer Law International. 1996.

SHELTON, Dinah. Manual of European Environmental Law. Cambridge: Grotuis Publications Limited. 1993.

KWAKWA, Edward. Regulating the International Economy. The role of law in international politics: essays in international relations and international law. Oxford: Oxford University Press. 2000. 
ORGANIZAÇÃO MUNDIAL PARA A COOPERAÇÃO E DESENVOLVIMENTO ECONÔMICOS (OCDE). La mano visible: asumir la responsabilidad por el desarrollo social. Informativo da OCDE: Genebra: 2000.

REPETTO, Robert. Complementaridades entre libre comercio internacional y políticas ambientales. Comercio Internacional y Medio Ambiente: Derecho, Economia y Política. Buenos Aires: Espaço Editorial. 1995.

SITGLITZ, Joseph. A globalização e seus malefícios. São Paulo: Futura. 2002.

TINKER, Catherine. State Responsability and the Precautionary Principle. The Precautionary Principle and International Law. Haia: Kluwer Law International. 1996.

TORRES, Ricardo Lobo. Curso de direito financeiro e tributário. 6. ed. Rio de Janeiro: Renovar, 1999.

WATHEN, Tom. Um guia para el comercio internacional y el medio ambiente. Comercio Internacional y Medio Ambiente: Derecho, Economia y Política. Buenos Aires: Espaço Editorial. 1995. 